\title{
Role of MicroRNAs in the Warburg Effect and Mitochondrial Metabolism in Cancer
}

\author{
Li-Hui Jin ${ }^{1}$, Chen Wei ${ }^{2 *}$
}

\begin{abstract}
Metabolism lies at the heart of cell biology. The metabolism of cancer cells is significantly different from that of their normal counterparts during tumorigenesis and progression. Elevated glucose metabolism is one of the hallmarks of cancer cells, even under aerobic conditions. The Warburg effect not only allows cancer cells to meet their high energy demands and supply biological materials for anabolic processes including nucleotide and lipid synthesis, but it also minimizes reactive oxygen species production in mitochondria, thereby providing a growth advantage for tumors. Indeed, the mitochondria also play a more essential role in tumor development. As information about the numorous microRNAs has emerged, the importance of metabolic phenotypes mediated by microRNAs in cancer is being increasingly emphasized. However, the consequences of dysregulation of Warburg effect and mitochondrial metabolism modulated by microRNAs in tumor initiation and progression are still largely unclear.
\end{abstract}

Keywords: Cancer - microRNAs - Warburg effect - mitochondria - metabolism

Asian Pac J Cancer Prev, 15 (17), 7015-7019

\section{Introduction}

Obtaining sufficient energy is a critical issue for cells to survive. In contract to normal counterparts, most cancer cells rely on aerobic glycolysis, a metabolic phenotype referred as the Warburg effect (Gatenby et al., 2004). A shift in glucose metabolism from oxidative phosphorylation to aerobic glycolysis is a unique biochemical characteristic of cancer cells (Hsu et al., 2008). This altered response is required to provide sufficient amounts of metabolic intermediates for cell anabolic phage (Lunt et al., 2011; Maria et al., 2013) (Figure 1). There is still controversial in the cancer metabolism, because mitochondria are still play a vital role in energy production in cancer.

MicroRNAs regulate gene expression at the posttranscriptional level, either by causing target mRNAs degradation or by suppression of target gene translation or by upregrulation of target mRNAs (Gigli et al., 2013). There is increasing evidence that a specific miRNA often regulates several target genes and one gene may be modulated by various miRNAs (Jackson et al., 2003). miRNAs are now considered a novel class of essential gene regulators for development and physiological processes (Ma et al., 2008).

Cancer cell metabolism is a multistep process controlled by some aberrant expression of both coding and non-coding gene. Recent studies have demonstrated that miRNAs play very critical roles in energy metabolism (Rottiers et al., 2012). The expression of a large number of oncogenes and tumor suppressor genes is regulated by miRNAs. miRNAs regulate several key enzymes and signaling hubs that cause alterations in tumor development (Singh et al., 2012). The complexity of miRNAs regulated cancer metabolism is only just beginning to understand for cancer researchers. Hence, in this review, we will focus on the importance of miRNAs on Warburg effect and mitochondrial metabolism in cancer.

\section{Expression of microRNAs in human cancer}

miRNAs play key roles in the development of human cancer, and expression profiles in human carcinoma

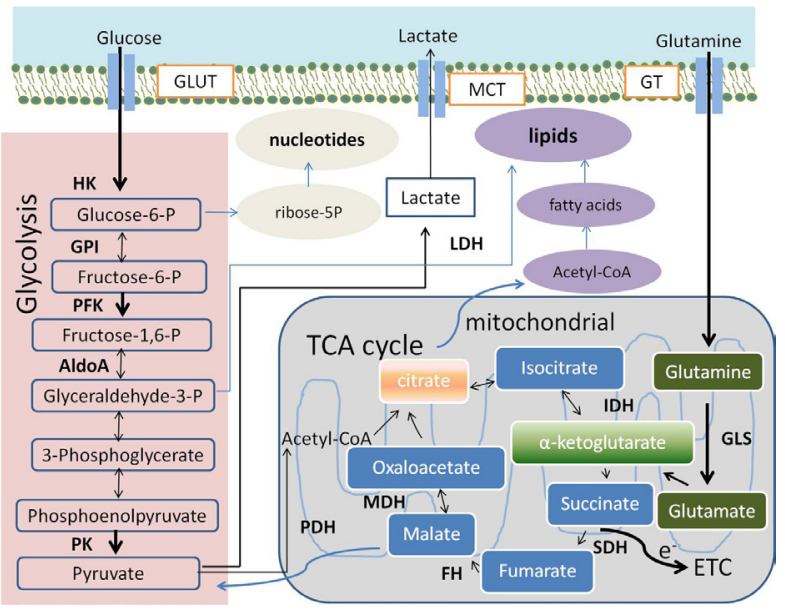

Figure 1. Metabolic Processes and Key Players in Cell Energy Supply

${ }^{I}$ Center for Translational Medicine, ${ }^{2}$ Clinical Laboratory, The First Affiliated Hospital, School of Medicine, Xi'an Jiaotong University, Xian, China*For correspondence: chenwei2011xjtu@gmail.com 
initiation, progression and prognosis (Volinia et al., 2013). There are over 1000 human miRNAs, and these miRNAs frequently are associated with tumor progression (You et al., 2012). The first evidence of the involvement of miRNAs in human cancer emanating from studies on chronic lymphocytic leukemia (CLL) by Croce's group. They reported that miR-15a and miR-16-1, which are deleted in human CLL samples (Iorio et al., 2012). Several studies have demonstrated that the alterations in expression of miRNAs contribute to human malignancies, including the program of initiation, development and metabolic reprogramming in human cancer (Croce et al., 2009; Garzon et al., 2009; Anaya-Ruiz et al., 2013; Li et al., 2013; Qi et al., 2013).

\section{Regulation of key enzymes of Warburg effect by miRNAs}

Many cancer cells choose to use glycolysis even in the presence of abundant oxygen. This phenomenon is termed as the Warburg effect, which is important for cancer cells to meet their energy needs and anabolic requirements. Indeed, several reports indicate that altered expression and activity of key glycoytic enzymes in tumor cells is driven by multiple factors, especially miRNAs (Table 1).

\section{Glucose transporters (GLUTs)}

Transportation of glucose across the plasma membrane of cancer cells is the first rate-limiting step for glucose metabolism and is mediated by facilitative glucose

Table 1. Summary of Enzymes Involved in Warburg Effect by miRNAs

\begin{tabular}{|c|c|c|c|}
\hline Gene & Upregulated & Downregulated & Reference \\
\hline \multicolumn{4}{|c|}{ Glucose transporters (GLUTs) } \\
\hline GLUT1 & $\begin{array}{l}\operatorname{miR}-19 a \\
\text { miR-19b, } \\
\text { miR-130b, } \\
\text { miR-301a }\end{array}$ & $\begin{array}{l}\operatorname{miR} 138, \operatorname{miR} 150 \\
\operatorname{miR} 199 a-5 p \\
\operatorname{miR} 532-5 p \\
\operatorname{miR} 1291\end{array}$ & $\begin{array}{l}\text { [Yamasaki et al, } \\
\text { Chow et al] }\end{array}$ \\
\hline GLUT3 & Unknown & $\operatorname{miR} 195-5 p$ & [Fei et al] \\
\hline GLUT4 & $\operatorname{miR}-223$ & $\begin{array}{l}\text { miR 93, miR- } \\
133, \text { miR-150 }\end{array}$ & $\begin{array}{l}\text { [Lu et al, Chen } \\
\text { et al, Srivastava } \\
\text { et al ] }\end{array}$ \\
\hline \multicolumn{4}{|c|}{ Glycolytic enzymes } \\
\hline HK2 & $\operatorname{miR}-155$ & $\operatorname{miR} 143$ & $\begin{array}{l}\text { [Fang et al, } \\
\text { Jiang et al] }\end{array}$ \\
\hline GPI & Unknown & $\begin{array}{l}\operatorname{miR} 200 s(\operatorname{miR} 200 \\
a / b / c), \operatorname{miR} 302 b, \\
m i R ~ 17-5 p\end{array}$ & $\begin{array}{l}\text { [Ahmad et al, } \\
\text { Rengaraj et al] }\end{array}$ \\
\hline AldoA & Unknown & $\begin{array}{l}\text { miR-122, miR- } \\
15 \mathrm{a} / 16-1\end{array}$ & $\begin{array}{l}\text { [Shea et al, } \\
\text { Calin et al] }\end{array}$ \\
\hline GAPDH & Unknown & $\operatorname{miR}-644 a$ & [Sikand et al] \\
\hline TPI1 & Unknown & $\begin{array}{l}\operatorname{miR}-195, \mathrm{miR}- \\
15 \mathrm{a} / 16-1\end{array}$ & $\begin{array}{l}\text { [Shea et al, } \\
\text { Calin et al] }\end{array}$ \\
\hline PKM2 & miR-99a & $\begin{array}{l}\text { miR } 133 \mathrm{a} / \mathrm{b}, \mathrm{miR}- \\
\text { 326, miR-124, } \\
\text { miR 137, miR-122, } \\
\text { miR-340 }\end{array}$ & $\begin{array}{l}\text { [Wong et al, } \\
\text { Kefas et al, } \\
\text { Li, et al , } \\
\text { Sun et al ] }\end{array}$ \\
\hline \multicolumn{4}{|l|}{ Lactate } \\
\hline LDHB & Unknown & $\operatorname{miR}-375$ & [Kinoshita et al] \\
\hline MCT1 & Unknown & $\mathrm{miR}-29 \mathrm{a} / \mathrm{b}, \mathrm{miR}-124$ & [Pullen et al ] \\
\hline Insulin & Unknown & $\begin{array}{l}\text { miR-103,miR-107, } \\
\text { miR-375, miR-29b }\end{array}$ & $\begin{array}{l}\text { [Trajkovski et al, } \\
\text { Zhao et al ,zhou } \\
\text { et al] }\end{array}$ \\
\hline
\end{tabular}

transporters (Macheda et al., 2005). miRNAs could regulate glucose uptake through mediating the GLUTs expression. miR-1291 has identified as a regulator of GLUT 1 in renal cell carcinoma (Yamasaki et al., 2013). Research in renal cell carcinoma showed that miR 138, miR 150, miR 199a-3p and miR 532-5p downregulate GLUT 1 expression, whereas miR 19a, miR-19b, miR 130b and miR 301a increase GLUT 1 expression (Chow et al., 2010). miR-195-5p suppresses glucose uptake and proliferation through suppression of GLUT3 expression in bladder cancer (Fei et al., 2012). It was confirmed that miR-133 reduced the level of GLUT4 (Horie et al., 2009). miR-223 have been reported that enhanced GLUT4 expression in cardiomyocyte glucose metabolism (Lu et al., 2010). The overexpression of miR-93 resulted in suppression of GLUT4 gene expression in polycystic ovary syndrome patients and women with insulin resistance (Chen et al., 2013). miR-150 has also been reported as a negative regulator of GLUT4 in pancreatic cancer cells (Srivastava et al., 2011).

\section{Glycolytic enzymes}

Studies showed that miRNAs regulate key enzymes of glycolysis in response to tumor needs. Hexokinases (HKs), four major isoforms: HK1-HK4, HK2 predominant overexpressed in cancer cells. miR-143, a negative regulator of HK2 (Fang et al., 2012; Jiang et al., 2012), miR-155 could indirectly promote HK2 transcription by repressing miR-143 in breast cancer cells (Jiang et al., 2012). Reports demonstrated that miR-200s is associated with regulation of GPI (Ahmad et al., 2011). In addition, GPI expression downregulated by miR-302b and miR-17$5 p$ in chicken primordial germ cells (Rengaraj et al., 2013). miR-122 decreases AldoA expression level in human liver cells (Shea et al., 2010). Additionally, miR-15a/16-1 cluster could inhibit AldoA and TPI1 (Calin et al., 2008). TPI1 also regulated by miR-195, which is significantly down-regulated in the bladder cancer (Ichimi et al., 2009). GAPDH has been used extensively for normalization of gene expression data. Recently, the report showed that

Table 2.Summary of Enzymes Involved in Mitochondria by miRNAs

\begin{tabular}{llll}
\hline Gene/Function & Upregulated & Downregulated & Reference \\
\hline $\begin{array}{l}\text { TCA cycle } \\
\text { Acetyl-CoA }\end{array}$ & $\begin{array}{l}\text { miR-103, } \\
\text { miR-107 }\end{array}$ & Unknown & [Wilfred et al] \\
IDH2 & Unknown & miR-183 & [Tanaka et al, \\
& & & Vohwinkel et al] \\
SDH & Unknown & miR-210 & [Shi et al] \\
ISCU1/2 & Unknown & miR-210 & [Shi et al] \\
MDH & Unknown & miR-743a & [Shi et al] \\
OXPHOS & & & \\
COXIV & miR-181c & miR-181c, & [Li et al, \\
& & miR-338 & Das et al] \\
ROS & miR-128a, & miR-17-92 & [Ebi et al, Venka \\
& miR-210, & miR-141, & taraman et al, \\
& miR-21, & miR-200a & Mateescu et al, \\
& miR-34a, & & Zhang et al, \\
& miR-193a-3p & & Li et al] \\
[Gao et al]
\end{tabular}


GAPDH are down-regulated by miR-644a. Nevertheless, this miRNA has not yet been described in relation to cancer (Sikand et al., 2012). PKM2 emerges as an important regulator in glycolytic process during cancer development (Sun et al., 2011). PKM2 is regulated by miRNAs, miR326, miR-133a and miR-133b significantly reduced in tumor cells by mediating PKM2 expression level (Wong et al., 2008; Kefas et al., 2010). Besides, miR-99a directly targets mTOR, then in turn increase PKM2 expression ( $\mathrm{Li}$ et al., 2013). miR-124, miR-137 and miR-340 inhibits the growth of colorectal cancer cells by counteracting the Warburg effect due to regulating alternative splicing of PKM gene from PKM2 to PKM1 (Sun et al., 2012).

\section{Lactate}

In the glycolytic process, most of the pyruvate is reduced to lactate in cancer cells. The lactate secreted outside the cells by monocarboxylate transports (MCTs) and converted into glucose to recycle back to the tumors. There is no major cancer-associated miRNAs are known to regulate the enzyme LDHA. However, three miRNAs, miR-29a, miR-29b and miR-124, selectively target MCT1 (Pullen et al., 2011). The expression of miR-375 is significantly reduced in cancer tissues of maxillary sinus squamous cell carcinoma (Kinoshita et al., 2012).

\section{Insulin}

Insulin acts in concerting with glucagon in regulation of glucose homeostasis. A growing experimental data shown that miRNAs involved in regulating the secretion and sensitivity of insulin. Silencing of miR-103 and miR107 have been identified that leads to improved glucose homeostasis and insulin selectivity (Trajkovski et al., 2011). miR-375 overexpression results in reduced glucoseinduced insulin secretion and its inhibition enhances insulin secretion (Zhao et al., 2010). The overexpression of miR 29a inhibits cellular proliferation and invasiveness by directly targeting glutamine synthetase in pancreatic cancer cell lines (Zhou et al., 2010).

\section{Regulation of mitochondria metabolism by microRNAs}

Mitochondria, are essential to the cell homeostasis maintenance. They play critical roles in regulation of cell events including proliferation, apoptosis, and generation of reactive oxygen species (ROS) (Bienertova-Vasku et al., 2013). Reprogramming of the energy metabolism in cancer cells, is associated mainly with the mitochondria. miRNAs have been reported to be participated in the regulation of mitochondrial function (Table 2), such as TCA cycle, production of ROS, glutamine metabolism and so on (Latronico et al., 2012; Bienertova-Vasku et al., 2013; Tomasetti et al., 2014).

\section{TCA cycle}

Cancer cells, rely more on aerobic glycolysis and less on TCA cycle. Moreover, this metabolic alteration ensures cells to generate multiple biosynthesis materials, while still providing abundant ATP. There is increasing evidence that miRNAs serve as regulators in controlling
TCA cycle. The first definite evidence that miR-103 and miR-107 participate in cellular acetyl-CoA and lipid synthesis through upregulating pantothenate kinase enzyme (Wilfred et al., 2007). mRNA and protein expression levels of IDH2 are downregulated by miR183 in glioma cells (Vohwinkel et al., 2011; Tanaka et al., 2013). SDH was validated as a bona fide miR-210 target. Recent evidence suggests that oxidative stress can elevate the activity of MDH thought reduction of miR-743a in a mouse hippocampal neuronal cell line (Shi et al., 2011). In addition, miR-378(*) leading to a reduction in TCA cycle gene expression and oxygen consumption (Eichner et al., 2010).

\section{OXPHOS}

Although our understanding of the role of miRNAs on regulation of OXPHOS is still far from complete, these are some studies have confirmed that some microRNAs participate in regulation of the ETC-related protein level. Overexpression of miR-338 results in a low COX IV mRNA as well as protein levels and can significantly reduce mitochondrial oxygen consumption, ATP production (Li et al., 2012). Overexpression of miR-181c results in down-regulation of COX1 protein and increased COX2 mRNA and protein levels, with an increase in both mitochondrial respiration and ROS generation in neonatal rat ventricular myocytes (Das et al., 2012).

\section{ROS}

Emerging research shown that ROS level mediated by microRNAs. The first evidence for the role of miRNAs on ROS production, miR-17-92 overexpression may serve as a fine-tuning influence to counterbalance the generation of DNA damage in RB-inactivated lung cancer cells (Ebi et al., 2009). miR-128a, increases intracellular ROS level and further impairs growth activity of medulloblastoma cells (Venkataraman et al., 2010). miR-141 and miR200 a, two members of the miR-200 family, act on ovarian tumorigenesis by targeting $\mathrm{p} 38 \alpha$ and modulate the oxidative stress response (Mateescu et al., 2011). In addition, miR-21 and miR-34a promotes tumor malignant growth and progression through its upregulation of cellular ROS levels (Zhang et al., 2012; Li et al., 2014).

\section{Glutamine metabolism}

Glutamine, is a major source of energy and nitrogen for biosynthetic pathways, and a carbon substrate for anabolic processes in cancer cells. Glutaminase is critical for mitochondrial metabolism, it converts glutamine to glutamate and ammonia. Myc as a transcriptional regulator, is necessary for cells to engage in glutaminolysis, which exceeds the cell requirement for nucleic acid and protein synthesis. A consequence of this Myc-dependent glutaminolysis is the alteration from mitochondrial metabolism to depend on glutamine catabolism to maintain cell viability and TCA cycle anapleurosis (Wise et al., 2008). Recent studies uncovered that miR-23a and miR-23b are suppressed by Myc, whereas, miR-23a/b is known to target and repress expression of glutaminase in human lymphoma and prostate cancer cells (Gao et al., 2009). 


\section{Mitochondrial dynamics}

Mitochondria are dynamic organelles, two necessary processes of fusion and fission are vital to the maintenance of organelle fidelity. Mitochondria fission is involved in the initation of apoptosis, the aberrant mitochondrial fission participates in the pathogenesis of many diseases including cancer. Studies have reported that miRNAs are able to regulate mitochondria fission machinery. miR384 is able to suppress mitochondria fission by targeting Fis1, which is necessary for mitochondrial fission and apoptosis (Wang et al., 2012). miR-30 family members inhibited mitochondrial fission through suppressing the expression of p53 and its downstream target dynaminrelated protein-1 (Drp1) (Li et al., 2010). Additionally, miR-499 can inhibit cardiomyocyte apoptosis through its suppression of calcineurin-mediated dephosphorylation of Drp-1 (Wang et al., 2011).

In conclusion, cancer metabolism and the role of miRNAs are rapidly growing research area. miRNAs participate in controlling cancer cell metabolic reprogramming, including glycolysis and mitochondrial energy metabolism. miRNAs play important roles by regulating the expression of gene that modulating the various metabolic phenotypes or metabolicrelated enzymes. Although Warburg was wrong about mitochondria, he was prescient in his focus on metabolism. Mitochondria represent an essential center of physiological processes of the cell, whose deregulation largely contributes to the cancer initiation and progression. Recently, many studies showed miRNAs as modulators of mitochondrial processes, including Warburg effect, which reinforce their importance in tumor biology, and highlight these gene regulators as promising therapeutic targets in cancers. Altered metabolism should now be considered a core hallmark of cancer. There is much work to be done.

\section{References}

Ahmad A, Aboukameel A, Kong D, et al (2011). Phosphoglucose isomerase/autocrine motility factor mediates epithelialmesenchymal transition regulated by miR-200 in breast cancer cells. Cancer Res, 71, 3400-9.

Anaya-Ruiz M, Bandala C, Perez-Santos JL (2013). MiR-485 acts as a tumor suppressor by inhibiting cell growth and migration in breast carcinoma T47D cells. Asian Pac $J$ Cancer Prev, 14, 3757-60.

Anaya-Ruiz M, Cebada J, Delgado-López G, et al (2013). MiR153 silencing induces apoptosis in the MDA-MB-231 breast cancer cell line. Asian Pac J Cancer Prev, 14, 2983-6.

Bienertova-Vasku J, Sana J, Slaby O (2013). The role of microRNAs in mitochondria in cancer. Cancer Lett, 336, 1-7.

Calin GA, Cimmino A, Fabbri M, et al (2008). MiR-15a and miR-16-1 cluster functions in human leukemia. Proc Natl Acad Sci USA, 105, 5166-71.

Chen YH, Heneidi S, Lee JM, et al (2013). MiRNA-93 inhibits GLUT4 and is overexpressed in adipose tissue of polycystic ovary syndrome patients and women with insulin resistance. Diabetes, 62, 2278-86.

Chow TF, Mankaruos M, Scorilas A, et al (2010). The miR-1792 cluster is over expressed in and has an oncogenic effect on renal cell carcinoma. J Urol, 183, 743-51.

Croce CM (2009). Causes and consequences of microRNA dysregulation in cancer. Nat Rev Genet, 10, 704-14.
Das S, Ferlito M, Kent OA, et al(2012). Nuclear miRNA regulates the mitochondrial genome in the heart. Circ Res, 110, 1596-603.

Ebi H, Sato T, Sugito N, et al (2009). Counterbalance between $\mathrm{RB}$ inactivation and miR-17-92 overexpression in reactive oxygen species and DNA damage induction in lung cancers. Oncogene, 28, 3371-9.

Eichner LJ, Perry MC, Dufour CR, et al (2010). MiR-378(*) mediates metabolic shift in breast cancer cells via the PGC1 beta/ERRgamma transcriptional pathway. Cell Metab, 12, 352-61.

Fang R, Xiao T, Fang Z, et al (2012). MicroRNA-143 (miR-143) regulates cancer glycolysis via targeting hexokinase 2 gene. J Biol Chem, 287, 23227-35.

Fei X, Qi M, Wu B, et al (2012). MicroRNA-195-5p suppresses glucose uptake and proliferation of human bladder cancer T24 cells by regulating GLUT3 expression. FEBS Lett, 586, 392-7.

Gao P, Tchernyshyov I, Chang TC, et al (2009). c-Myc suppression of miR-23a/b enhances mitochondrial glutaminase expression and glutamine metabolism. Nature, 458, 762-5.

Garzon R, Calin GA, Croce CM (2009). MicroRNAs in Cancer. Annu Rev Med, 60, 167-79.

Gatenby RA, Gillies RJ (2004). Why do cancers have high aerobic glycolysis? Nat Rev Cancer, 4, 891-9.

Gigli I, Maizon DO (2013). MicroRNAs and the mammary gland: A new understanding of gene expression. Genet Mol Biol, 36, 465-74.

Hatziapostolou M, Polytarchou C, Iliopoulos D(2013). miRNAs link metabolic reprogramming to oncogenesis. Trends Endocrinol Metab, 24, 361-73.

Horie T, Ono K, Nishi H, et al (2009). MicroRNA-133 regulates the expression of GLUT4 by targeting KLF15 and is involved in metabolic control in cardiac myocytes. Biochem Biophys Res Commun, 389, 315-20.

Hsu PP, Sabatini DM (2008). Cancer cell metabolism: Warburg and beyond. Cell, 134, 703-7.

Ichimi T, Enokida H, Okuno Y, et al (2009). Identification of novel microRNA targets based on microRNA signatures in bladder cancer. Int J Cancer Suppl, 125, 345-52.

Iorio MV, Croce CM (2012). MicroRNA dysregulation in cancer: diagnostics, monitoring and therapeutics. A comprehensive review. EMBO Mol Med, 4, 143-59.

Jackson AL, Bartz SR, Schelter J, et al (2003). Expression profiling reveals off-target gene regulation by RNAi. Nat Biotechnol, 21, 635-7.

Jiang S, Zhang LF, Zhang HW, et al (2012). A novel miR$155 /$ miR-143 cascade controls glycolysis by regulating hexokinase 2 in breast cancer cells. EMBO J, 31, 1985-98.

Kefas B, Comeau, L, Erdle N, et al (2010). Pyruvate kinase M2 is a target of the tumor-suppressive microRNA-326 and regulates the survival of glioma cells. Neuro Oncol, 12, 1102-12.

Kinoshita T, Nohata N, Yoshino H, et al (2012). Tumor suppressive microRNA-375 regulates lactate dehydrogenase $\mathrm{B}$ in maxillary sinus squamous cell carcinoma. Int J Oncol, 40, 185-93.

Latronico MV, Condorelli G (2012). The might of microRNA in mitochondria. Circ Res, 110, 1540-2.

Li J, Donath S, Li Y, et al (2010). MiR-30 regulates mitochondrial fission through targeting p53 and the dynamin-related protein-1 pathway. PLoS Genet, 6, e1000795.

Li J, Xu ZW, Wang KH, et al (2013). Networks of MicroRNAs and genes in retinoblastomas. APJCP, 14, 6631-6.

Li P, Jiao J, Gao G, et al (2012). Control of mitochondrial activity by miRNAs. J Cell Biochem, 113, 1104-10. 
Li SZ, Hu YY, Zhao J, et al (2014). MicroRNA-34a induces apoptosis in the human glioma cell line, A172, through enhanced ROS production and NOX2 expression. Biochem Biophys Res Commun, 444, 6-12.

Li W, Wang J, Chen QD, et al (2013). Insulin promotes glucose consumption via regulation of $\mathrm{miR}-99 \mathrm{a} / \mathrm{mTOR} / \mathrm{PKM} 2$ pathway. PloS one, $\mathbf{8}$, e 64924.

Lu H. Buchan RJ, Cook SA (2010). MicroRNA-223 regulates Glut4 expression and cardiomyocyte glucose metabolism. Cardiovasc Res, 86, 410-20.

Lunt SY, Vander Heiden MG (2011). Aerobic glycolysis: meeting the metabolic requirements of cell proliferation. Annu Rev Cell Dev Biol, 27, 441-4.

Macheda ML, Rogers S, Best JD (2005). Molecular and cellular regulation of glucose transporter (GLUT) proteins in cancer. $J$ Cell Physiol, 202, 654-62.

Ma L, Weinberg RA (2008). Micromanagers of malignancy: role of microRNAs in regulating metastasis.Trends Genet, 24, 448-56.

Mateescu B, Batista L, Cardon M, et al (2011). MiR-141 and miR-200a act on ovarian tumorigenesis by controlling oxidative stress response. Nat Med, 17, 1627-35.

Pullen TJ, Silva Xavier G, Kelsey G, et al(2011). MiR-29a and miR-29b contribute to pancreatic beta-cell-specific silencing of monocarboxylate transporter 1 (Mct1). Mol Cell Biol, 31, 3182-94.

Qi B , Yao WJ, Zhao BS, et al (2003). Involvement of microRNA-198 overexpression in the poor prognosis of esophageal cancer. APJCP, 14, 5073-6.

Rengaraj D, Park TS, Lee SI, et al (2013). Regulation of glucose phosphate isomerase by the 3'UTR-specific miRNAs miR$302 \mathrm{~b}$ and miR-17-5p in chicken primordial germ cells. Biol Reprod, 89, 33.

Rottiers V, Naar AM (2012). MicroRNAs in metabolism and metabolic disorders. Nat Rev Mol Cell Biol, 13, 239-50.

Shea CM, Tzertzinis G (2010). Controlled expression of functional miR-122 with a ligand inducible expression system. BMC Biotechnol, 10, 76.

Shi Q, Gibson GE (2011). Up-regulation of the mitochondrial malate dehydrogenase by oxidative stress is mediated by miR-743a. J Neurochem, 118, 440-8.

Sikand K, Singh J, Ebron JS, et al (2012). Housekeeping gene selection advisory: glyceraldehyde-3-phosphate dehydrogenase (GAPDH) and beta-actin are targets of miR644a. PloS one, 7, e47510.

Singh PK, Brand RE, Mehla K (2012). MicroRNAs in pancreatic cancer metabolism. Nat Rev Gastroenterol Hepatol, 9 , 334-44.

Srivastava SK, BhardwajA, Singh S, et al (2011). MicroRNA-150 directly targets MUC4 and suppresses growth and malignant behavior of pancreatic cancer cells. Carcinogenesis, 32, 1832-9.

Sun Q, Chen X, Ma J, et al (2011). Mammalian target of rapamycin up-regulation of pyruvate kinase isoenzyme type M2 is critical for aerobic glycolysis and tumor growth. Proc Natl Acad Sci USA, 108, 4129-34.

Sun Y, Zhao X, Zhou Y, et al (2012). MiR-124, miR-137 and miR-340 regulate colorectal cancer growth via inhibition of the Warburg effect. Oncol Rep, 28, 1346-52.

Tanaka H, Sasayama T, Tanaka K, et al (2013). MicroRNA-183 upregulates HIF-1 alpha by targeting isocitrate dehydrogenase 2 (IDH2) in glioma cells. J Neurooncol, 111, 273-83.

Tomasetti M, Neuzil J, Dong L (2014). MicroRNAs as regulators of mitochondrial function: role in cancer suppression. Biochim Biophys Acta, 1840, 1441-53.

Trajkovski M, Hausser J, Soutschek J, et al (2011). MicroRNAs 103 and 107 regulate insulin sensitivity. Nature, 474, 649-53.
Venkataraman S, Alimova I, Fan R, et al (2010). MicroRNA 128a increases intracellular ROS level by targeting Bmi-1 and inhibits medulloblastoma cancer cell growth by promoting senescence. PloS one, 5, e10748.

Vohwinkel CU, Lecuona E, Sun H, et al (2011). Elevated CO(2) levels cause mitochondrial dysfunction and impair cell proliferation. J Biol Chem, 286, 37067-76.

Volinia S, Croce CM (2013). Prognostic microRNA/mRNA signature from the integrated analysis of patients with invasive breast cancer. Proc Natl Acad Sci US A, 110, 7413-7.

Wang JX, Jiao JQ, Li Q, et al (2011). MiR-499 regulates mitochondrial dynamics by targeting calcineurin and dynamin-related protein-1. Nat Med, 17, 71-8.

Wang K, Long B, Jiao JQ, et al (2012). MiR-484 regulates mitochondrial network through targeting Fis1. Nat Commun, 3,781 .

Wilfred BR, Wang WX, Nelson PT (2007). Energizing miRNA research: a review of the role of miRNAs in lipid metabolism, with a prediction that miR-103/107 regulates human metabolic pathways. Mol Genet Metab, 91, 209-17.

Wise DR, DeBerardinis RJ, Mancuso A, et al (2008). Myc regulates a transcriptional program that stimulates mitochondrial glutaminolysis and leads to glutamine addiction. Proc Natl Acad Sci USA, 105, 18782-7.

Wong TS, Liu XB., Chung-Wai HoA, et al (2008). Identification of pyruvate kinase type M2 as potential oncoprotein in squamous cell carcinoma of tongue through microRNA profiling. Int J Cancer Suppl, 123, 251-7.

Yamasaki T, Seki N, Yoshino H, et al (2013). Tumor-suppressive microRNA-1291 directly regulates glucose transporter 1 in renal cell carcinoma. Cancer Sci, 104, 1411-9.

You JS, Jones PA (2012). Cancer genetics and epigenetics: two sides of the same coin? Cancer Cell, 22, 9-20

Zhang X, Ng W L, Wang P, et al (2012). MicroRNA-21 modulates the levels of reactive oxygen species by targeting SOD3 and TNFalpha. Cancer Res, 72, 4707-13.

Zhao H, Guan J, Lee HM, et al (2010). Up-regulated pancreatic tissue microRNA-375 associates with human type 2 diabetes through beta-cell deficit and islet amyloid deposition. Pancreas, 39, 843-6.

Zhou Q, Souba WW, Croce CM, et al (2010). MicroRNA-29a regulates intestinal membrane permeability in patients with irritable bowel syndrome. Gut, 59, 775-84. 